\title{
Calcium Ionophore-Induced Extracellular Vesicles Mediate Cytoprotection against Simulated Ischemia/ Reperfusion Injury in Cardiomyocyte-Derived Cell Lines by Inducing Heme Oxygenase 1
}

\author{
Peter Pečan ${ }^{1,2,+}$, Szabolcs Hambalkó ${ }^{3,+} \oplus$, Van Thai Ha ${ }^{1,2,+}$, Csilla T. Nagy ${ }^{3}$, Csilla Pelyhe ${ }^{3}(\mathbb{D}$, \\ Duško Lainšček ${ }^{1,4}$, Bence Kenyeres ${ }^{3}$, Gábor B. Brenner ${ }^{3}$, Anikó Görbe ${ }^{3,5}$, Ágnes Kittel ${ }^{6}(\mathbb{D}$, \\ Monika Barteková ${ }^{7,8}$ (D) , Péter Ferdinandy ${ }^{3,5}$, Mateja Manček-Keber 1,4,*(D) and Zoltán Giricz ${ }^{3,5, *}$ \\ 1 National Institute of Chemistry, SI-1000 Ljubljana, Slovenia; peter.pecan@ki.si (P.P.); vanthai.ha@ki.si (V.T.H.); \\ dusko.lainscek@ki.si (D.L.) \\ 2 Graduate School of Biomedicine, Faculty of Medicine, University of Ljubljana, SI-1000 Ljubljana, Slovenia \\ 3 Department of Pharmacology and Pharmacotherapy, Semmelweis University, 1085 Budapest, Hungary; \\ hambalko.szabolcs@med.semmelweis-univ.hu (S.H.); nagy.csilla@med.semmelweis-univ.hu (C.T.N.); \\ pelyhe.csilla@med.semmelweis-univ.hu (C.P.); bencekenyeres@gmail.com (B.K.); \\ brenner.gabor@med.semmelweis-univ.hu (G.B.B.); gorbe.aniko@med.semmelweis-univ.hu (A.G.); \\ peter.ferdinandy@pharmahungary.com (P.F.) \\ 4 Centre of Excelence EN-FIST, SI-1000 Ljubljana, Slovenia \\ 5 Pharmahungary Group, 6722 Szeged, Hungary \\ 6 Institute of Experimental Medicine, ELRN, 1083 Budapest, Hungary; kittel.agnes@koki.hu \\ 7 Centre of Experimental Medicine, Institute for Heart Research, Slovak Academy of Sciences, \\ 84104 Bratislava, Slovakia; monika.bartekova@savba.sk \\ 8 Institute of Physiology, Faculty of Medicine, Comenius University in Bratislava, 81372 Bratislava, Slovakia \\ * Correspondence: mateja.mancek@ki.si (M.M.-K.); giricz.zoltan@med.semmelweis-univ.hu (Z.G.); \\ Tel.: +386-1-476-0393 (M.M.-K.); +36-1-210-4416 (Z.G.) \\ + These authors contributed equally to this work.
}

Received: 10 July 2020; Accepted: 14 October 2020; Published: 16 October 2020

\begin{abstract}
Cardioprotection against ischemia/reperfusion injury is still an unmet clinical need. The transient activation of Toll-like receptors (TLRs) has been implicated in cardioprotection, which may be achieved by treatment with blood-derived extracellular vesicles (EVs). However, since the isolation of EVs from blood takes considerable effort, the aim of our study was to establish a cellular model from which cardioprotective EVs can be isolated in a well-reproducible manner. EV release was induced in HEK293 cells with calcium ionophore A23187. EVs were characterized and cytoprotection was assessed in $\mathrm{H} 9 \mathrm{c} 2$ and $\mathrm{AC} 16$ cell lines. Cardioprotection afforded by EVs and its mechanism were investigated after $16 \mathrm{~h}$ simulated ischemia and $2 \mathrm{~h}$ reperfusion. The induction of HEK293 cells by calcium ionophore resulted in the release of heterogenous populations of EVs. In H9c2 and AC16 cells, stressEVs induced the downstream signaling of TLR4 and heme oxygenase 1 (HO-1) expression in H9c2 cells. StressEVs decreased necrosis due to simulated ischemia/reperfusion injury in H9c2 and AC16 cells, which was independent of TLR4 induction, but not that of HO-1. Calcium ionophore-induced EVs exert cytoprotection by inducing HO-1 in a TLR4-independent manner.
\end{abstract}

Keywords: extracellular vesicles; TLR4; HO-1; cardioprotection; ischemia/reperfusion injury

\section{Introduction}

In ischemic heart disease, one of the leading causes of death-ischemia/reperfusion ( $\mathrm{I} / \mathrm{R})$ injury -induces different cell death programs, e.g., necrotic and apoptotic pathways (as reviewed in [1]). 
Despite the intensive research activity in the field over the last 40 years, there is an unmet clinical need for efficacious cardioprotective treatments or interventions [2,3]. A number of mediators and mechanisms have been proposed to be involved in experimental cardioprotective mechanisms, for example, the activation of protein kinase C (PKC), nuclear factor kappa-B (NF-kB), or nitric oxide (NO) pathways (reviewed in $[4,5]$ ). In addition, several mediators that can promote cytoprotective responses in the heart, such as heat shock proteins (HSPs) as representatives of damage-associated molecular patterns (DAMPs) [6], adenosine [7], or tumor necrosis factor alpha (TNF $\alpha$ ), have been identified [8]. However, to date, no pharmacological tool has reached clinical application for inducing cardioprotection [9]. Therefore, the development of novel cardioprotective treatments is of primary importance.

Extracellular vesicles (EVs) are membrane-bound particles released by most mammalian cells via diverse mechanisms. They contain a vast array of signaling molecules, rendering EVs prime vehicles of intercellular communication in physiological and pathological processes $[10,11]$. The use of EVs as experimental therapeutic agents is emerging [12-15]. Our study was the first to show that EVs were involved in cardioprotection afforded by remote ischemic conditioning (RIC) [16], and studying their use as cardioprotective agents has become popular in recent years [14,17]. Although several mechanisms have been proposed in EV-initiated cardioprotection, to date, none of them have been proven to be sufficiently potent or reproducible to initiate clinical studies with EV-based therapeutic options.

Oxidized phospholipids (oxPLs) are formed in cardiomyocytes after I/R as a result of oxidative burst [18] and can act as DAMPs. We have previously shown that oxPLs generated by oxidative stress can be released from the cells in EVs which induce innate immune responses $[19,20]$. Although oxPLs may have detrimental effects on cardiomyocytes [18], they have been shown to induce cytoprotective effects in cells against subsequent oxidative stress situations when added in low concentrations [21]. This adaptive response is mediated by the NF-E2-related factor 2/Kelch-like ECH-associated protein 1 (Nrf2/Keap-1) pathway and involves the expression of antioxidant proteins, such as heme oxygenase-1 (HO-1) and thioredoxin reductase 1 (TR1) [22]. A similar response has been observed in macrophages when stimulated with oxPLs and was identified as oxPL-induced macrophage phenotype Mox [23].

Toll-like receptors (TLRs) are evolutionarily conserved proteins present at the membrane surface of immune cells, including dendritic cells, macrophages, natural killer cells, and T and B lymphocytes, but also of non-immune cardiac cells, such as endothelial cells, fibroblasts, and cardiomyocytes [24]. TLRs play a central role in the activation of the innate immune system. These "pattern recognition receptors" (PRRs) recognize microbial molecules termed "pathogen-associated molecular patterns" (PAMPs) and DAMPs, such as oxPLs. Therefore, TLRs discriminate between "self" and "non-self" and activate the innate immune inflammatory response [25]. TLRs, mainly TLR2 and TLR4, have been shown to be associated with cardiovascular disease, as well as with cardioprotection afforded by different interventions [26,27]. It is well-documented that inflammation via TLR-mediated MyD88-dependent $\mathrm{NF}-\mathrm{KB}$ activation plays an important cytoprotective role in myocardial I/R injury [28], whereas TLR4 is also associated with cardioprotection by the activation of PI3K/Akt signaling, suggesting that there is a crosstalk between TLR and PI3K/Akt pathways in myocardial I/R injury and cardioprotection [29]. Furthermore, the activation or direct supplementation of a major downstream mediator of TLR4 with the tumor necrosis factor alpha (TNF $\alpha$ ) was shown to be cardioprotective, even in a large animal model of cardiac I/R injury $[8,30,31]$, which indicates that TLR signaling may be a viable target for novel cardioprotective interventions.

The activation of TLR signaling has also been associated with cardioprotection mediated by EVs. Vicencio et al. documented that the EV-rich fraction isolated from rat and human blood was cardioprotective in different models of cardiac I/R injury [32]. This protection was prevented by the inhibition of HSP70 and by blocking TLR4 in cardiomyocytes, indicating that EVs deliver endogenous protective signals to the heart via a pathway involving TLR4 and cardioprotective HSPs [32]. Very recently, it has also been documented that exosomes derived from miR-146a-modified adipose-derived stem cells decreased the infarct size and reversed myocardial infarction-induced 
TLR4/NF- KB activation in rats [33]. Since EVs have been shown to be involved in RIC [16], it seems that TLR signaling might mediate EV-induced cardioprotection. However, to utilize TLR-modulating EVs as therapeutic tools, EVs and methods of their production have to meet certain criteria in terms of safety, efficacy, and reproducibility.

To date, TLR4-inducing EVs have only been isolated from blood. In spite of the rapid evolution of EV isolation technologies, EVs obtained from blood have been proven to contain various impurities, and methods are still cumbersome and have moderate yields at best [34-36]. In contrast, EVs isolated by more robust methods, such as ultracentrifugation from cell lines that are cultured in well-regulated conditions in chemically defined media, may suffice for the expectations of therapeutic systems. On top of culturing parameters, triggers for EV release can be more standardized in cell cultures than in in vivo interventions. We have previously shown that calcium ionophore A23187, which induces oxidative stress, stimulates the shedding of EVs from human embryonal kidney 293 (HEK 293) cells that activate TLR4 via oxPLs $[19,20]$, indicating that non-microbial signals may also be sufficient for triggering cardioprotection via TLR4 induction.

The aims of this study were to decipher whether stressEVs released after A23187 calcium ionophore treatment, which has the ability to induce the release of TLR4-activating EVs from cell cultures, can induce signaling in $\mathrm{H} 9 \mathrm{c} 2$ and AC16 heart-derived proliferating cell lines and to assess if such EVs are capable of inducing cardioprotection against acute I/R injury. We showed that stressEVs induced TLR4-dependent signaling in macrophages and H9c2 and AC16 cells, but only induced adaptive signaling in heart-derived cells. Furthermore, adaptive signaling induced by stressEVs contributed to cardioprotection via HO-1 activity in a TLR4-independent manner.

\section{Results}

\subsection{Calcium-Ionophore Treatment Induces the Release of StressEVs from HEK293 Cells}

Dynamic light scattering (DLS) analysis revealed that particles (referred to as stressEVs) that were released after HEK293 cells were treated with A23187 included large EVs (100-1000 nm in diameter) and a population with a diameter smaller than $100 \mathrm{~nm}$ (small EVs). A minor subpopulation with a diameter greater than $1000 \mathrm{~nm}$ was also present in the stressEV preparations (Figure 1A). Nanoparticle tracking analysis (NTA) also confirmed that stressEV preparations were dominated by EVs with an average size of $250 \mathrm{~nm}$ (Figure 1B). Electron microscopic imaging confirmed the presence of EVs in our stressEV preparations (Figure 1C, black arrows). The presence of presumably nuclear material was also evident in certain EVs (Figure 1C, white arrow).

To further describe the contents of our stressEV preparations, we performed Western blot analysis against Alix and TSG101, which are well-accepted markers of EVs. By detecting histone H3 in EV preparations, we also confirmed the presence of nuclear material (Figure 1D). However, the absence of the cleaved caspase 3 signal proved that our EV preparations did not contain apoptotic bodies). StressEVs were then separated by density gradient ultracentrifugation, which revealed that EV markers CD81 (in Fraction 7), TSG101 (in Fraction 7 and 8), and calnexin (in Fraction 6-8), as well as membrane marker annexin V (in Fraction 3-8), appeared at the density range characteristic of EVs (Figure 1E). Differences in the marker distribution also implied the heterogeneity of stressEVs. 

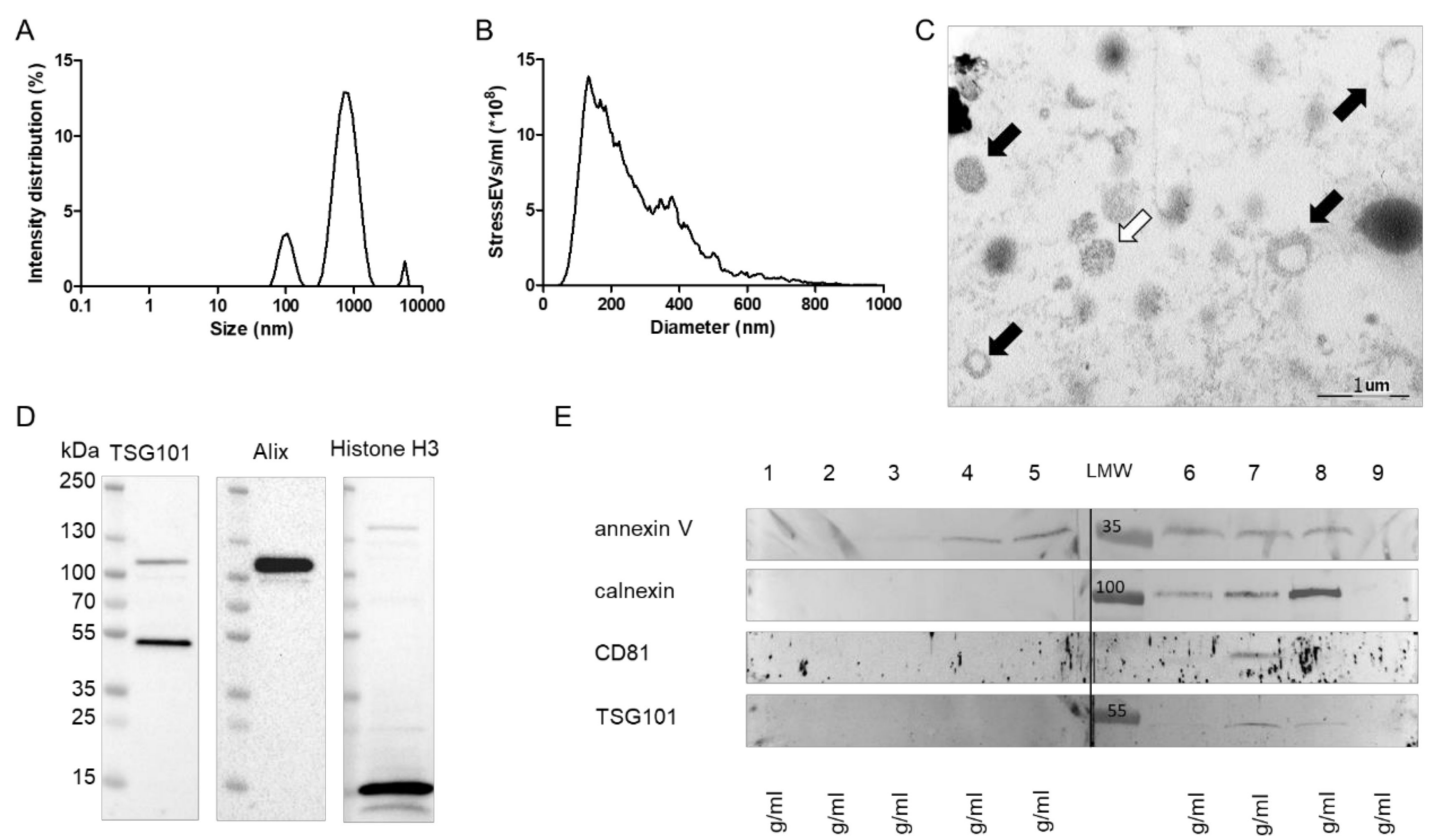

E

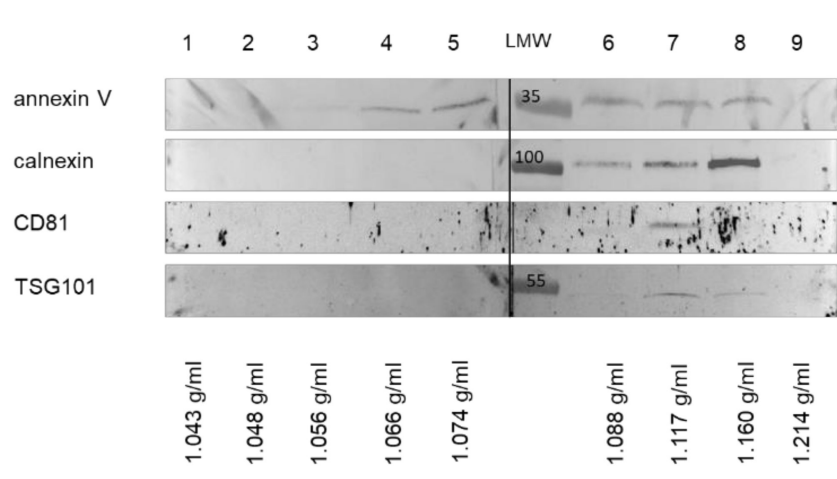

Figure 1. Characterization of stressextracellular vesicles (EVs). HEK293 cells were treated with calcium ionophore for $1 \mathrm{~h}$ and stressEVs were isolated. (A) Dynamic Light Scattering (DLS) analysis of an isolate showing the intensity distribution of EVs. (B) Nanoparticle tracking analysis (NTA) of EV preparations. (C) Electron microscopic images of a representative EV preparation. Black arrows: EVs, and white arrow: nuclear material. (D,E) Western blot analysis of EVs showing that EVs and nuclear material were present in our preparations.

\subsection{StressEVs Activate the TLR4 Receptor, but Not the Adaptive Response in Macrophages}

StressEVs induced TLR4 receptor signaling, which was confirmed first by NF- $\mathrm{kB}$ activation in HEK293T cells expressing the TLR4/MD-2/CD14 receptor complex treated with increasing concentrations of stressEVs in the presence or absence of TLR4 inhibitor TAK-242 (Figure 2A). For the positive control, we used lipopolysaccharide (LPS).

StressEVs were shown to promote inflammation in a TLR4-dependent manner through oxPLs $[19,20]$. OxPLs were shown to induce a special type of macrophages-a Mox type [23]-determined with the expression of Nrf2-mediated redox-regulatory genes, such as Hmox1, with protective effects. Pro-inflammatory Il6 (Figure 2B,C) and inducible NOS (iNos) (Figure 2D) mRNA expression, but not Hmox1 or Txnrd1 expression, was detected in mouse macrophages after stressEV stimulation (Figure 2E,F). Similarly, stressEVs did not influence the HO-1 protein expression in macrophages (Figure $2 \mathrm{G}, \mathrm{H}$ ). These data show that stressEVs induce pro-inflammatory cytokines in a TLR4-dependent manner, but are not able to induce a Mox phenotype or adaptive response in macrophages. 
A

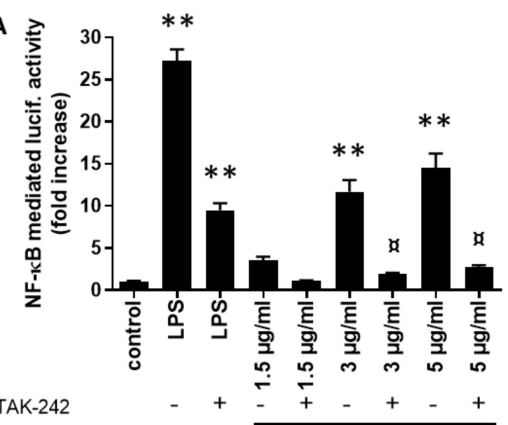

B

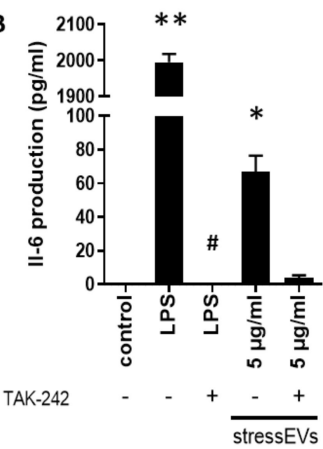

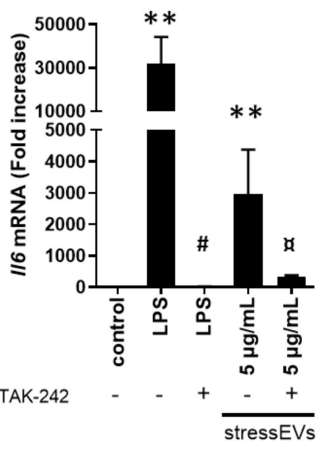
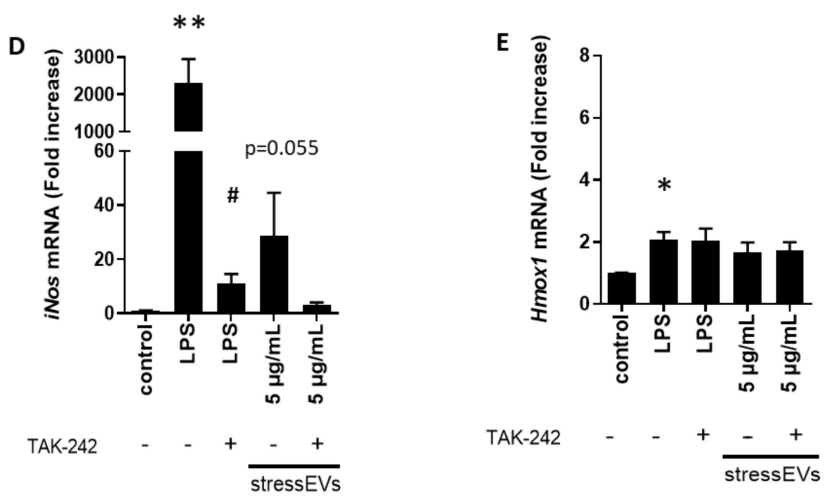

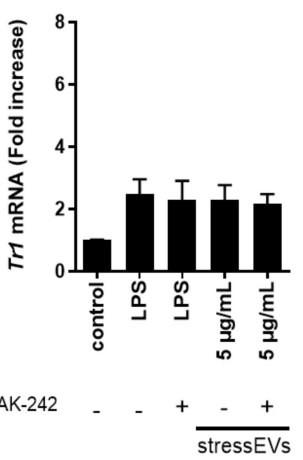

H
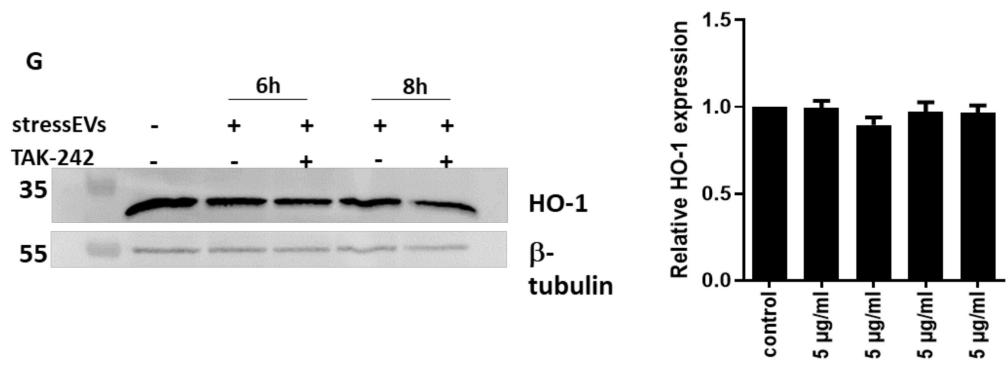

TAK-242

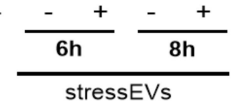

Figure 2. StressEVs activate TLR4, but do not induce an adaptive response in macrophages. (A) HEK293T cells were transfected with plasmids for hTLR4, hMD-2/CD14, firefly luciferase under the nuclear factor kappa-B (NF-kB) promoter, and Renilla luciferase for normalization. Cells were stimulated with stressEVs $(1.5,3$, or $5 \mu \mathrm{g} / \mathrm{mL})$ or lipopolysaccharide (LPS) $(10 \mathrm{ng} / \mathrm{mL})$ for $24 \mathrm{~h}$, with or without $2.5 \mu \mathrm{M}$ TAK-242. A dual luciferase test was performed. Negative controls were transfected but unstimulated cells. Data were pooled from two independent experiments $\left(n=6{ }^{* *} p<0.01\right.$ vs. control; $a p<0.05$ vs. stressEVs). (B-F) Macrophages were stimulated for $6 \mathrm{~h}$ (16 h for ELISA) with stressEVs $(5 \mu \mathrm{g} / \mathrm{mL})$ or LPS $(10 \mathrm{ng} / \mathrm{mL})$ in the absence or presence of TAK-242 $(2.5 \mu \mathrm{M})$. Il6, iNos, Txnrd1, and Hmox1 mRNA levels were determined using qPCR and Il-6 by ELISA, respectively. $(\mathbf{G}, \mathbf{H})$ Macrophages were stimulated for 6 or $8 \mathrm{~h}$ with stressEVs $(5 \mu \mathrm{g} / \mathrm{mL})$ in the absence or presence of TAK-242 $(2.5 \mu \mathrm{M})$. Heme oxygenase 1 (HO-1) expression was detected using WB. $\beta$-tubulin expression was used as the loading control. Data were pooled from four $(\mathbf{C}-\mathbf{F} ; n=5)$ or two $(\mathbf{B} ; n=6)$ independent experiments ( ${ }^{*} p<0.05$ vs. control; ${ }^{* *} p<0.01$ vs. control; $\# p<0.05$ vs. LPS; a $p<0.05$ vs. stressEVs). WB is a representative of two independent experiments and optical density plot analysis of band intensities $(\mathbf{H})$ was performed from two independent experiments. 


\subsection{StressEVs Activate Cardioprotective Signaling in H9c2 and AC16 Cell Lines}

Furthermore, we investigated the effect of stressEVs on the mRNA expression of genes downstream of TLR4 in H9c2 cells. Both LPS and EVs induced the expression of Tnfa and iNOS mRNA (Figure 3A and Supplementary Figure S1). Preincubation of the cells using the TLR4 inhibitor TAK-242 decreased Tnfa and iNOS expression after LPS, as well as stressEV stimulation, confirming TLR4-dependent signaling (Figure 3A and Supplementary Figure S1). Interestingly, the expression of pro-inflammatory Il6, which was strongly expressed in macrophages (Figure 2B), was minor, but still TLR4-dependent (Figure 3B). H9c2 cells are poor producers of pro-inflammatory cytokines after TLR4 activation [37,38]. Due to a low mRNA expression, we were unable to detect cytokines in the supernatant. On the other hand, the mRNA expression of cytoprotective genes Hmox1 (HO-1) and Txnrd1 (TR1) was elevated in the stressEV-treated groups compared to the control (Figure 3C-F). TLR4 ligand LPS did not induce their expression, suggesting that stressEVs might influence cytoprotective pathways via signaling mechanisms other than TLR4 in H9c2 cells. As expected, TAK-242 inhibited all LPS-induced gene expression in H9c2 cells (Figure 3), but it was not able to inhibit Hmox1 mRNA and protein expression after stressEV stimulation. Moreover, the expression of HO-1 after stressEV and TAK-242 treatment was even increased on mRNA, as well as the protein level (Figure 3C,E,F).

A

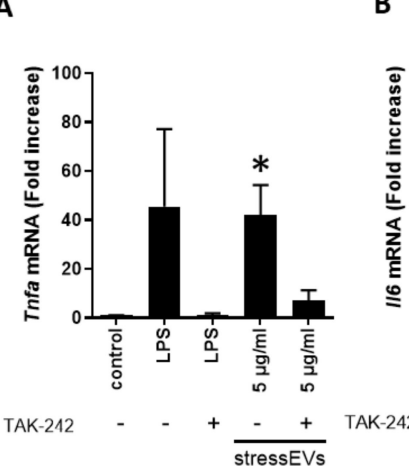

E
B

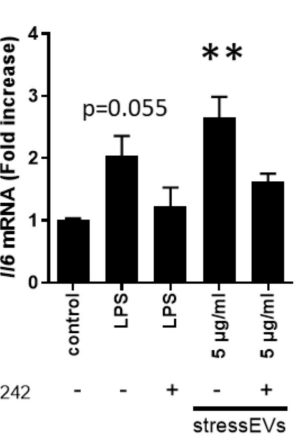

C

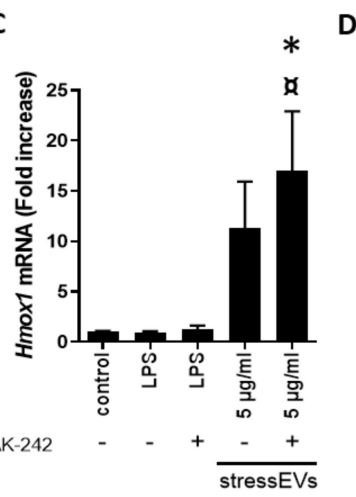

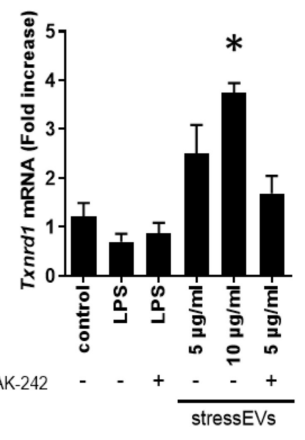

F

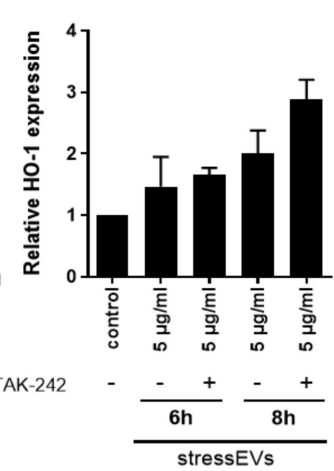

Figure 3. StressEVs activate cardioprotective signaling pathways in H9c2 cells, independently of TLR4 signaling. (A-D) H9c2 cells were stimulated for $6 \mathrm{~h}$ with stressEVs $(5$ or $10 \mu \mathrm{g} / \mathrm{mL})$ or LPS $(10 \mathrm{ng} / \mathrm{mL})$ in the absence or presence of TAK-242 $(2.5 \mu \mathrm{M})$. Tnfa Il6, Txnrd1, and Hmox1 mRNA levels were determined using qPCR. Data were pooled from four independent experiments $\left(n=5 ;{ }^{*} p<0.05\right.$ vs. control; ${ }^{* *} p<0.01$ vs. control; $a p<0.05$ vs. stressEVs). (E,F) H9c2 cells were stimulated for 6 or $8 \mathrm{~h}$ with stressEVs $(5 \mu \mathrm{g} / \mathrm{mL})$ in the absence or presence of TAK-242 $(2.5 \mu \mathrm{M})$. HO-1 expression was detected using WB. $\beta$-actin expression was used as the loading control. WB is a representative of two independent experiments and optical density plot analysis of band intensities $(\mathbf{F})$ was performed from two independent experiments. 
We also assessed the key transcriptional effects of stressEVs in AC16 human cardiomyoblast cells. Similar to what was seen in H9c2 cells, we found that IL6 gene and protein expression was induced by stressEVs and secretion was decreased by TLR4 inhibition (Figure 4A,B). However, in contrast to the data from $\mathrm{H} 9 \mathrm{c} 2$ cells, TNFA mRNA was below the detection limit, and HMOX1 expression was not elevated by stressEVs in AC16; only a tendency was observed when stressEVs were applied in combination with the TLR4 inhibitor TAK-242 and when they were treated with the TLR4-inducer LPS (Figure 4C), which indicates that HMOX1 may be under complex regulation by TLR4 in AC16 cells.
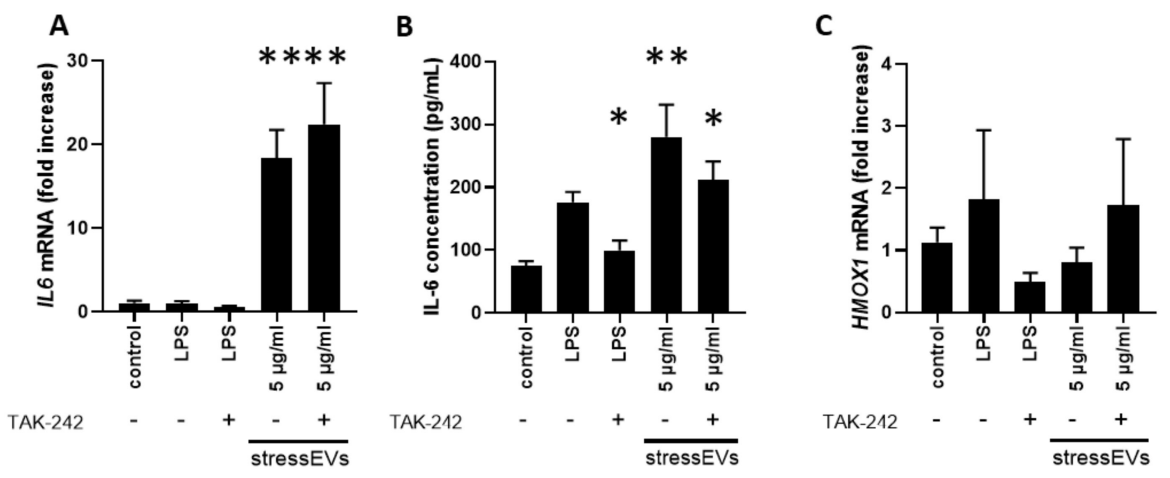

Figure 4. StressEVs activate interleukin signaling in AC16 cells. AC16 cells were stimulated for $6 \mathrm{~h}$ with stressEVs $(5 \mu \mathrm{g} / \mathrm{mL})$ or LPS $(10 \mathrm{ng} / \mathrm{mL})$ in the absence or presence of TAK-242 $(2.5 \mu \mathrm{M})$. IL6 and HMOX1 mRNA levels were determined by $\mathrm{qPCR}(\mathbf{A}, \mathbf{C})\left(n=6 ;{ }^{* *} p<0.01\right.$ vs. control), and IL-6 expression was detected using ELISA (B) $\left(n=3 ;{ }^{* *} p<0.01\right.$ vs. control; ${ }^{*} p<0.05$ vs. control).

2.4. StressEVs Protect against Simulated I/R-Induced Cytotoxicity via the Induction of HO-1, Independently of TLR4 Receptor Signaling

As stressEVs induced protective signaling in $\mathrm{H} 9 \mathrm{c} 2$ and AC16 cells, we were interested whether they can have cardioprotective effects.

We investigated whether stressEVs induce apoptosis in H9c2 and AC16 cells to assess their safety in cardiomyocytes. StressEVs up to a $2 \mu \mathrm{g} / \mathrm{mL}$ concentration did not induce apoptosis in any of the cell lines. In AC16 cells, a $5 \mu \mathrm{g} / \mathrm{mL}$ concentration triggered caspase 3/7 activation; however, stressEV-treated H9c2 cells did not induce apoptosis (Figure 5A,B).

A

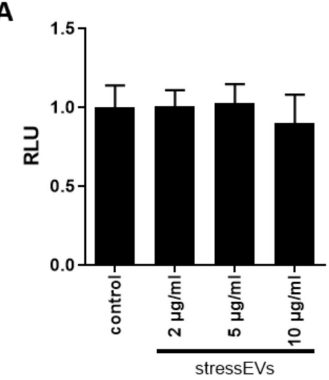

B

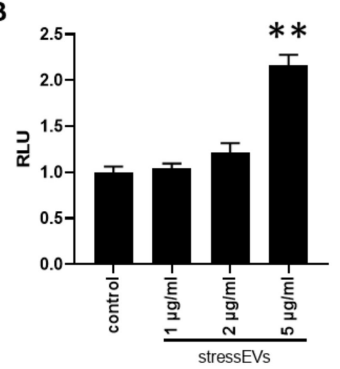

Figure 5. StressEVs do not activate apoptosis or induce cytotoxicity. (A,B) Caspase 3/7 activity was measured after $4 \mathrm{~h}$ incubation of the $\mathrm{H} 9 \mathrm{c} 2(\mathbf{A})$ or $\mathrm{AC} 16$ (B) cells with increasing concentrations of stresses. Data were pooled from three $(\mathbf{A} ; n=9 ; \mathbf{B} ; n=6)$ independent experiments $\left({ }^{* *} p<0.01 \mathrm{vs}\right.$. control).

We also evaluated the toxicity of stressEVs. As shown in Figure 6A, low concentrations of EVs have no negative effect on the viability of $\mathrm{H} 9 \mathrm{c} 2$ cells in normoxic conditions. The highest examined concentration of stressEVs $(10 \mu \mathrm{g} / \mathrm{mL})$ decreased the viability of $\mathrm{H} 9 \mathrm{c} 2$ cells moderately, similar to their apoptotic effects (Figure 5A). Therefore, a maximum of $5 \mu \mathrm{g} / \mathrm{mL}$ was used for further experiments. We investigated the potential cytoprotective effects of a pretreatment with stressEVs on rodent $\mathrm{H} 9 \mathrm{c} 2$ 
(Figure 6B) or human AC16 (Figure 6E) cells subjected to simulated I/R. The cytoprotective effect of stressEVs was observed by measuring the release of LDH from H9c2 cells (Figure 6B) or by measuring the viability (Figure 6D) or cell death (Figure $6 \mathrm{D}$ ) in AC16 cells after $16 \mathrm{~h}$ of ischemia under $1 \% \mathrm{O}_{2}$ in hypoxic solution and $2 \mathrm{~h}$ of reoxygenation in media. Therefore, stressEVs released after calcium ionophore treatment showed a protective effect against $\mathrm{I} / \mathrm{R}$ in heart-derived human and rodent cell lines.

A

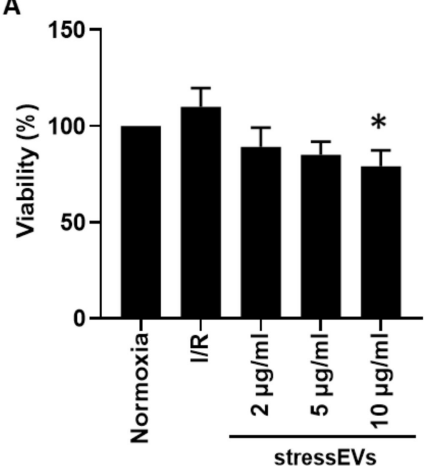

B

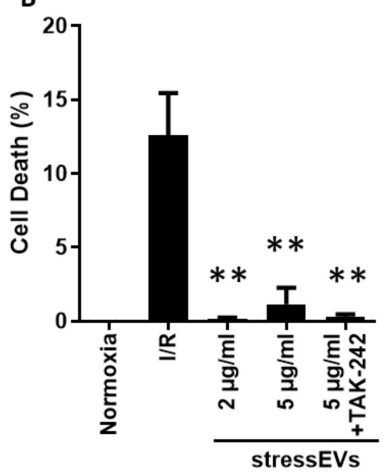

C

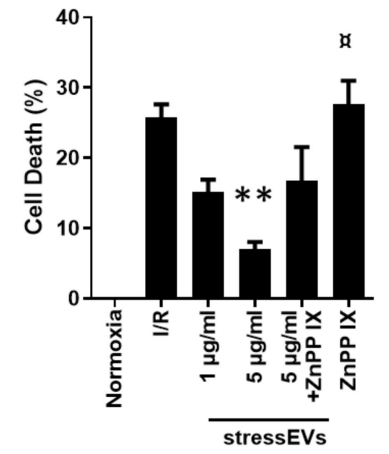

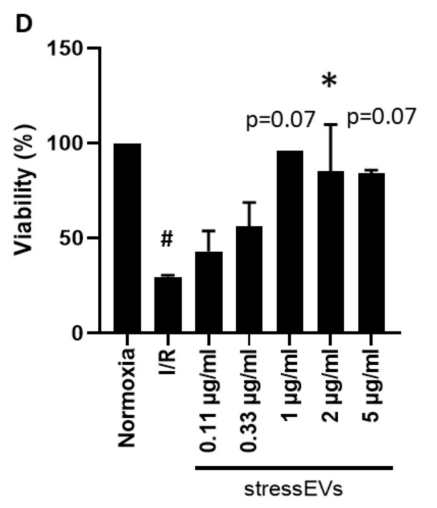

E

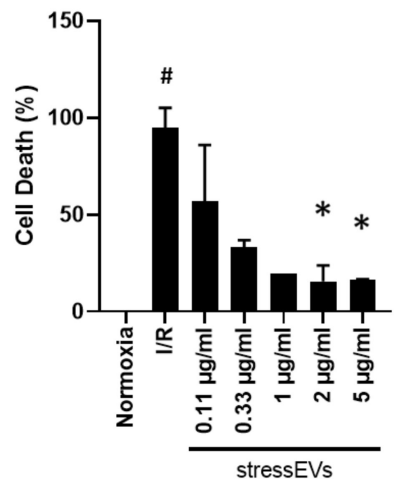

Figure 6. StressEVs protect against simulated I/R-induced cytotoxicity via HO-1 activity. (A) H9c2 cells were incubated for $4 \mathrm{~h}$ with increasing concentrations of stressEVs in normoxic conditions. The cell viability of $\mathrm{H} 9 \mathrm{c} 2$ cells was determined by the Calcein-AM assay. (B,C) H9c2 cells were pre-incubated with either TAK-242 $(2.5 \mu \mathrm{M})$ or ZnPP IX $(1 \mu \mathrm{M})$ for $1 \mathrm{~h}$ prior to stressEV stimulation (1 or 2 and $5 \mu \mathrm{g} / \mathrm{mL}$ ) for $6 \mathrm{~h}$ before $\mathrm{I} / \mathrm{R}$. LDH release was determined. (D,E) AC16 cells were preincubated with stressEVs $(0.1-5 \mu \mathrm{g} / \mathrm{mL})$ for $4 \mathrm{~h}$ before $\mathrm{I} / \mathrm{R}$. Viability was measured by the Calcein-AM assay (D) and cytotoxicity was determined by the CytoTox-Glo assay (E). Data are representative of three $(\mathbf{A}-\mathbf{C} ; n=5)$ or two (D-E; $n=6)$ independent experiments ${ }^{*} p<0.05 * *<0.01$ vs. I/R; \# $p<0.05$ vs. normoxia; a $p<0.05$ vs. $5 \mu \mathrm{g} / \mathrm{mL}$ stressEVs + ZnPP IX).

To decipher the molecular mechanism responsible for the cytoprotective effect of stressEVs, we decided to assess whether it could be abolished by the inhibition of TLR4 signaling. We observed that the inhibition of TLR4 signaling by TAK-242 did not abolish cytoprotection by EVs in H9c2 cells (Figure 6B), which suggests that our EV preparations induced their cytoprotective effects via signaling pathways other than TLR4. In adaptive response situations induced by lipid peroxidation products, cytoprotection is mediated through the Nrf2 pathway, where HO-1 is mainly expressed [22]. The role of increased HO-1 expression in cardioprotection has also already been described [39]. As we observed an increased expression of HO-1, we were interested whether stressEVs mediate cytoprotection through HO-1. Indeed, cytoprotection by stressEVs was reduced by the inhibition of HO-1 by the co-treatment of H9c2 cells with HO-1 inhibitor zinc protoporphyrine IX (ZnPP IX) (Figure 6C). These results indicate that the cytoprotective effect of EVs is mediated through HO-1 via mechanisms independent of TLR4 
signaling in H9c2 cells. Similar results were obtained in AC16 human cells, showing that 2 to $5 \mu \mathrm{g} / \mathrm{mL}$ stressEVs decreased sI/R-induced cell death (Figure 6D,E).

\section{Discussion}

Here, we present evidence that a short time exposure of HEK293 cells to calcium ionophore A23187 triggers stressEV release, which induces TLR4 signaling and pro-survival mechanisms in H9c2 and AC16 cells, but not in macrophages. Furthermore, we provide evidence that the cytoprotection afforded by calcium ionophore-induced stressEVs is mediated by HO-1, independently of their effect on TLR signaling.

The characterization of stressEVs revealed several EV markers. Interestingly, there was a strong presence of annexin $\mathrm{V}$ in almost all fractions after gradient ultracentrifugation and a minor presence of calnexin in higher density fractions, indicating that stressEV preparations consist of several types of EVs. The presence of annexin V may be related to the formation of stressEVs, since Gong et al. showed that MLKL-dependent Ca-influx promoted phosphatidylserine exposure and that ESCRT-III facilitates the shedding of damaged annexin V plasma membrane bubbles, thus contributing to cell survival [40].

As stressEVs were shown to activate TLR4 through oxPLs $[19,20]$, we were interested whether they can induce cardioprotection. StressEVs are released after applying oxidative stress to the cells. Oxidative stress damages all biologically important molecules and some act as DAMPs. Our results on the induction of TLR4 confirm previous findings that EVs can induce an immune response [6,32], but on the contrary, TLR4-dependent activation was not cardioprotective. H9c2 and AC16 cells seem to express low amounts of TLR4 or poorly express pro-inflammatory cytokines. Although the mRNA expression of Tnfa was evident and TLR4-dependent, we and also others [37] were not able to detect cytokine secretion from the H9c2 cell line, or it was low when a very high amount of LPS $(10 \mu \mathrm{g} / \mathrm{mL})$ was used [38], but intracellular pathways were activated. As the direct supplementation of TNF $\alpha$ can achieve cardioprotection [8], this might be the reason we were unable to observe it and it also implies the indirect role of TLR4 signaling in cardioprotection. In addition, although Davidson et al. and Vicencio et al. showed that rat and human EVs isolated from blood induced cardioprotection through HSP70 and TLR4 signaling [6,32], Davidson also showed that EVs isolated from HUVEC cells protected cardiomyocytes from I/R, although no HSP70 was detected. These observations and ours here, that stressEVs protect AC16 cells, even in the absence of the induction of HMOX1, show that yet to be identified signaling pathways are also involved in cardioprotection by EVs.

EVs are very complex entities, where various molecules may influence an unknown number of signaling pathways. This might be a drawback of EV therapies, as we also showed that stressEVs may only have a narrow therapeutic window, since higher doses of stressEVs decreased the viability of $\mathrm{H} 9 \mathrm{c} 2$ cells and induced apoptosis, even in normoxic conditions. Nevertheless, since, in this study, EV release was triggered under well-controlled, chemically-defined conditions, the obtained stressEVs might show a safety profile that may afford translation of the current results, which is substantiated by the finding that cardioprotection was achieved in heart-derived proliferating cells of rat and human origin, despite the induction of pro-inflammatory signaling pathways.

Here, we found that the induction of an antioxidant response via the upregulation of HO- 1 and TR1 expression may be a direct mechanism of the cardioprotective effects of stressEVs in H9c2 and AC16 and that TLR4 induction might even be dispensable for cytoprotection. HO-1 induction was previously found to convey cytoprotective effects against various harmful stimuli, including high glucose- or cobalt-induced chemical stress in cardiomyocytes [41] and hypoxia-induced injury in H9c2 cells [42,43], and against coronary occlusion-induced I/R injury in vivo [44]. However, the latter study found that HO-1 induction reduced plasma TNF $\alpha$ levels [44], which is in contrast to our finding. The induction of antioxidant systems, in particular the HO-1, was achieved via the application of EVs. In a study by Mahmoud et al., TNF $\alpha$-stimulated endothelial cell-derived EVs protected recipient cells against oxidative stress [45], but their effects on cardiomyocytes were not assessed. $\operatorname{Tr} 1$ plays a role in restoring oxidized proteins via thioredoxin, which alleviates the effects of myocardial infarction [46]. 
These findings demonstrate that oxidative stress, including cardiac I/R injury, can be alleviated by stressEVs via the induction of pro-survival programs.

As stressEVs were unable to induce HO-1 or TR1 in macrophages, we concluded that their contribution to the cardioprotection induced by stressEVs may not be significant. On the other hand, the results from $\mathrm{I} / \mathrm{R}$ experiments on $\mathrm{H} 9 \mathrm{c} 2$ cells imply that stressEV-mediated protection was due to an increased $\mathrm{HO}-1$ expression in $\mathrm{H} 9 \mathrm{c} 2$ and $\mathrm{AC} 16$ cells and that the inhibition of pro-inflammatory signaling might contribute to higher protection. This is in agreement with some previous observations, where the innate immune system in the acute response to $\mathrm{I} / \mathrm{R}$ contributed to cell death and myocardial infarction (reviewed in [47]).

In summary, here, we demonstrated, for the first time, that EVs released from cells cultured in vitro as a consequence of calcium ionophore treatment can be utilized as a treatment option against simulated I/R injury in cardiac myocytes and that the key mechanism of this cytoprotective signal is the induction of antioxidant pathways such as HO-1 and TR1. Based on these results, we suggest that calcium ionophore-induced stressEVs may reveal novel avenues for cardioprotective treatments against ischemic cardiac disease such as myocardial infarction.

\section{Materials and Methods}

\subsection{Reagents}

All reagents were purchased from Merck (Darmstadt, Germany), unless otherwise noted. LPS (from Salmonella abortus equi HL83) was received from K. Brandenburg (Forschungszentrum Borstel, Germany). TAK-242 (CLI-095) was purchased from InvivoGen (San Diego, CA, USA).

\subsection{Cell Culturing}

HEK293 and HEK293T cells were grown in DMEM containing 10\% heat-inactivated fetal bovine serum (FBS) (both Invitrogen Life Technologies, Carlsbad, CA, USA). Mouse macrophages (immortalized BMDMs) were grown in RPMI 1640 containing 10\% heat-inactivated FBS (both Invitrogen Life Technologies). H9c2 rat cardiomyoblast cells and AC16 human cardiac cells were obtained from ECACC and cultured in high glucose ( $4500 \mathrm{mg} / \mathrm{L})$ Dulbecco's modified Eagle's medium (DMEM) supplemented with $10 \%$ FBS, $2 \mathrm{mM}$ glutamine, and $100 \mathrm{U} / \mathrm{mL}$ of penicillin and streptomycin.

\subsection{Isolation and Characterization of StressEVs}

HEK293 cells were seeded at a $1.5 \times 10^{6}$ cells/mL density in DMEM containing $10 \%$ heat-inactivated FBS (Invitrogen). The next day, growth media were removed and cells were washed with HBSS. Next, we stimulated the cells with $10 \mu \mathrm{M}$ calcium ionophore A23187 in HBSS buffer (Invitrogen) containing $2.5 \mathrm{mM} \mathrm{CaCl}_{2}$ without FBS. StressEVs were collected after $1 \mathrm{~h}$ stimulation of HEK293 cells. To remove cells, supernatants were centrifuged at $800 \times g$. StressEVs were isolated by ultracentrifugation at $100,000 \times g$ (rotor type 50TI; Beckman Coulter) two times. StressEVs were resuspended in PBS and their concentration was determined by the BCA assay.

To further analyze stressEVs, gradient ultracentrifugation was performed. OptiPrep ( $60 w / v \%$ iodixanol was diluted to $40 \%, 20 \%, 10 \%$, and $5 \%$ in $0.25 \mathrm{M}$ sucrose in $10 \mathrm{mM}$ Tris- $\mathrm{HCl}, \mathrm{pH} 7.5$ ) and a discontinuous gradient were formed by layering $2.5 \mathrm{~mL}$ of each solution in $10 \mathrm{~mL}$ polypropylene centrifugation tubes (Beckman Coulter, Miami, FL, USA). A total of $250 \mu \mathrm{L}(120 \mu \mathrm{g})$ of stressEVs was layered on the top. The samples were centrifuged at $100,000 \times g$ (rotor type 50TI, Beckman Coulter) for $16 \mathrm{~h}$ at $4{ }^{\circ} \mathrm{C}$. Then, $1 \mathrm{~mL}$ fractions of density gradient layers were collected from the top (Fraction 1-Fraction 9). The density of fractions was calculated based on the iodixanol concentration measured by spectrophotometry at $340 \mathrm{~nm}$ on SynergyMx (BioTek, Winooski, VT, USA).

The hydrodynamic average particle size of stressEVs was measured by the Zetasizer Nano (Malvern Instruments, Malvern Hills, UK) Dynamic Light Scattering (DLS) apparatus at $20{ }^{\circ} \mathrm{C}$, using an angle of $173 \mathrm{o}$ and a 633-nm laser. 
The size distribution of stressEVs was assessed by nanoparticle tracking analysis by the Nanosight NS300 instrument (488 nm laser) connected to a sample assistant for automated sample processing (both Malvern Panalytical, UK) with a constant syringe pump flow. Five recordings of $60 \mathrm{~s}$ were performed and captured at camera level 13. After a visual inspection of all records, the raw data were analysed using the NanoSight NTA 3.3 software (Malvern Panalytical, Malvern, UK). Automatic settings were selected for the minimum expected particle size and blur, the minimum track length was set to 10 , the detection threshold to 5 , the sample viscosity to the corresponding viscosity for water, and the temperature to $25^{\circ} \mathrm{C}$. The output data were calculated as the EV size (mean and modal hydrodynamic diameter in $\mathrm{nm}$ ).

EVs were visualized by transmission electron microscopy. Vesicle pellets were fixed with $4 \%$ formaldehyde, postfixed in $1 \% \mathrm{OsO}_{4}$. EVs were block-stained with $1 \%$ uranyl acetate in $50 \%$ ethanol, and then dehydrated in graded ethanol and embedded in Taab 812 (Taab Laboratories, Aldermaston, UK). Ultrathin sections were cut and analyzed with a Hitachi 7100 electron microscope.

For Western blotting, H9c2 cells were seeded at $1 \times 10^{6}$ cells/well in a 6-well plate and were preincubated with TAK-242, where indicated, for $1 \mathrm{~h}$ prior to stressEV $(5 \mu \mathrm{g} / \mathrm{mL})$ stimulation for 6 or $8 \mathrm{~h}$. Cells were washed with PBS and lysed in $100 \mu \mathrm{L}$. Cell or stressEV samples were lysed in radioimmunoprecipitation assay buffer (Cell Signaling Technology, Danvers, MA, USA) supplemented with $1 \mathrm{mM}$ PMSF (Roche, Basel, Switzerland), $0.1 \mathrm{mM}$ sodium fluoride, $200 \mathrm{mM}$ sodium orthovanadate, and complete protease inhibitor cocktail (Roche). SDS-PAGE and WB were performed. Primary antibodies used were anti-TSG101 (Abcam, Cambridge, UK ab83), anti-Alix, anti-histone H3 and anti-cleaved caspase 3 (Cell Signaling Technology \#2171, \#4499 and \#9664), anti-annexin V (ab108194), anti-calnexin (ab22595), anti-heme oxygenase 1 (ab13243; Abcam), and anti-CD81 (sc-166029, Santa Cruz Biotechnology, Dallas, TX, USA). Horseradish peroxidase-conjugated secondary antibodies were used to detect the proteins.

\subsection{Assessment of TLR4 Induction and the Activation of Cardioprotective Signaling}

HEK293T cells $\left(2 \times 10^{4}\right.$ cells/well $)$ were transfected with expression plasmids for $p$ Flag-CMV-hTLR4 (a gift from Carsten Kirschning, University of Duisburg-Essen,Germany), pDUO-hMD-2/hCD14 (Invivogen), pELAM1-luciferase (NF- $\mathrm{KB}$ promotor) (a gift from Carsten Kirschning), and phRL-TK Renilla luciferase (Promega, Madison, WI, USA) using PEI transfection reagent (12 $\mu \mathrm{L} / 1 \mu \mathrm{g}$ DNA). Cells were stimulated with stressEVs or LPS as a positive control for $24 \mathrm{~h}$. Cells were lysed and analyzed for luciferase activity using a dual luciferase assay on the Orion luminometer (Berthold).

Where indicated, cells were preincubated with TAK-242 $(2.5 \mu \mathrm{M})$ for $1 \mathrm{~h}$ prior to stressEVs or LPS (as a positive control) for $6 \mathrm{~h}$. Total RNA was isolated using TRIZOL reagent (Roche). cDNA was prepared using a high capacity cDNA reverse transcription kit (Applied Biosystems, Foster City, CA, USA) and qPCR for Il6, iNos, Hmox1, Tnfa, Il6, Hmox1, and Txnrd1 was performed using the SYBR green I master kit (Roche) on LightCycler 480 (Roche). The results are displayed as the cycle of quantification $(\mathrm{Cq})$ expression relative to Gapdh and presented as the fold increase relative to untreated cells (primer sequences are given in Table 1).

Table 1. Primers used for qPCR.

\begin{tabular}{ccc}
\hline Mouse & Forward $\mathbf{5}^{\prime} \rightarrow \mathbf{3}^{\prime}$ & Reverse $^{\prime} \mathbf{5}^{\prime} \mathbf{3}^{\prime}$ \\
\hline Gapdh & TTCACCACCATGGAGAAGGC & GGCATGGACTGTGGTCATGA \\
Il1beta & AAGGAGAACCAAGCAACGACAAAA & TGGGGAACTCTGCAGACTCAAACT \\
Hmox1 & CAGGATTTGTCTGAGGCCTT & CATAGACTGGGTTCTGCTTGT \\
Txnrd1 & GCTGGTCTTGGATTTTGTCAC & CTTCACTGTGTCTTCGACTTTC \\
Il6 & CGGAGGCTTAATTACACATGTTC & CTGGCTTTGTCTTTCTTGTTATC \\
iNos & GCCATTGAGTTCATCAACCAGTA & CTGGTAGGTTCCTGTTGTTTCTA \\
\hline
\end{tabular}


Table 1. Cont.

\begin{tabular}{ccc}
\hline Rat & Forward $\mathbf{5}^{\prime} \boldsymbol{\rightarrow} \mathbf{3}^{\prime}$ & Reverse $^{\prime} \mathbf{5}^{\prime} \rightarrow \mathbf{3}^{\prime}$ \\
\hline Gapdh & GTATTGGGCGCCTGGTCACC & CGCTCCTGGAAGATGGTGATGG \\
Tnfalpha & ACTGAACTTCGGGGTGATTG & GCTTGGTGGTTTGCTACGAC \\
Hmox1 & GATTTGTCCGAGGCCTTGAA & GTTCTGCTTGTTTCGCTCTATC \\
Il6 & TGATGGATGCTTCCAAACTG & GAGCATTGGAAGTTGGGGTA \\
Txnrd1 & GCCAAATTTGACAAGAAGGTGA & CTTTCAGAGCTTGTCCTAACAGA \\
\hline Human & Forward $\mathbf{5}^{\prime} \rightarrow \mathbf{3}^{\prime}$ & Reverse $\mathbf{5}^{\prime} \boldsymbol{\rightarrow} \mathbf{3}^{\prime}$ \\
\hline HPRT & AGATGGTCAAGGTCGCAAG & TTCATTATAGTCAAGGGCATATCC \\
TNFA & CCTGTGAGGAGGACGAAC & CGAAGTGGTGGTCTTGTTG \\
HMOX1 & GCCCCAGGATTTGTCAGAG & CATAGATGTGGTACAGGGAG \\
IL6 & ACAGCCACTCACCTCTTC & AAGTCTCCTCATTGAATCCAG \\
\hline
\end{tabular}

\subsection{Assessment of Toxicity and Cardioprotection by EVs}

$\mathrm{H} 9 \mathrm{c} 2$ cells were seeded in 96-well plates at 104/well in normal growth medium. After $24 \mathrm{~h}$, growth media were replaced with growth media containing a vehicle or EV in increasing doses and the cells were kept in a $\mathrm{CO}_{2}$ incubator (Scancell-Labogene, Lynge, Denmark) for $4 \mathrm{~h}$. Then, in groups of cells, growth media were replaced for $16 \mathrm{~h}$ with either normoxic solution (in $\mathrm{mM}: \mathrm{NaCl} 125, \mathrm{KCl} 5.4$, $\mathrm{NaH}_{2} \mathrm{PO}_{4}$ 1.2, $\mathrm{MgCl}_{2}$ 0.5, HEPES 20, $\mathrm{MgSO}_{4}, 1.3, \mathrm{CaCl}_{2}$, glucose 15, taurine 5, creatine-monohydrate 2.5 and BSA $0.1 \%, \mathrm{pH} 7.4$ ) in a $\mathrm{CO}_{2}$ incubator (Norm groups) or hypoxic solution (in mM: $\mathrm{NaCl} 119$, $\mathrm{KCl}$ 5.4, $\mathrm{MgSO}_{4}$ 1.3, $\mathrm{NaH}_{2} \mathrm{PO}_{4}$ 1.2, HEPES 5, $\mathrm{MgCl}_{2}$ 0.5, $\mathrm{CaCl}_{2}$ 0.9, Na-lactate 20, BSA 0.1\% pH 6.4; $\mathrm{I} / \mathrm{R}$ groups) in a three-gas $\left(95 \% \mathrm{~N}_{2}\right.$ and $5 \% \mathrm{CO}_{2}$, with a maximum of $1 \% \mathrm{O}_{2}$ ) incubator (Panasonic Healthcare Co., Ltd., Gunma, Japan), both containing the above-mentioned doses of EVs or vehicle only [48]. Following the $16 \mathrm{~h}$ normoxic or simulated I/R conditions, cells were kept in growth medium in an incubator supplied with $95 \%$ air and $5 \% \mathrm{CO}_{2}$.

To assess the cell viability, calcein staining was performed as described previously [49]. Briefly, cells were washed with warm DPBS and calcein solution $(1 \mu \mathrm{M})$ was added and incubated for 30 min at room temperature in a dark chamber. Then, the calcein solution was replaced with fresh DPBS. An unbiased evaluation was performed by automatic detection of the fluorescence intensity of each well by the Varioskan Lux multimode microplate reader (Thermo Fisher Scientific, Waltham, MA, USA) at a temperature of $37^{\circ} \mathrm{C}$; excitation wavelength of $490 \mathrm{~nm}$, and emission wavelength of: $520 \mathrm{~nm}$. Cell survival results are shown as relative fluorescence units (RFU) normalized to that of the normoxic group (Norm).

Necrotic cell death due to simulated I/R or stressEV treatment was assessed from cell supernatants of $\mathrm{H} 9 \mathrm{c} 2$ cardiomyoblasts. Cells were seeded in 96-well plates at $3 \times 10^{4} /$ well in DMEM (with 4.5 $\mathrm{g} / \mathrm{L}$ glucose) containing 10\% heat-inactivated FBS. The next day, cells were pretreated with TAK-242 $(2.5 \mu \mathrm{M})$ or ZnPP IX $(1 \mu \mathrm{M})$ for $1 \mathrm{~h}$ and stimulated with stressEVs $(1 \mathrm{or} 5 \mu \mathrm{g} / \mathrm{mL})$ for $6 \mathrm{~h}$ under normal $\mathrm{O}_{2}$. Then, in groups of cells, growth media were replaced for $16 \mathrm{~h}$ with either normoxic solution under normal $\mathrm{O}_{2}$ or with hypoxic solution in a three-gas incubator, as above. Following the $16 \mathrm{~h}$ normoxic or $\mathrm{sI} / \mathrm{R}$ conditions, cells were kept in growth medium in an incubator under normal $\mathrm{O}_{2}$. For the LDH assay, the supernatant of cells was acquired by centrifugation, for $3 \mathrm{~min}$ at $250 \times g$, and analyzed for the presence of LDH activity with the CyQUANT LDH Cytotoxicity Assay (Thermo Fisher Scientific). Absorbance at $490 \mathrm{~nm}$ was measured using the SynergyMx (BioTek, Winooski, VT, USA) multiplate reader. Supernatant from cells, treated with $1 \%$ detergent Triton X-100, was used as a positive control (100\% LDH release), and supernatant from untreated cells was used as a negative control.

Cell viability was also assessed in AC16 cells by the CytoTox-Glo cytotoxicity assay (Promega, Madison, WI, USA), according to manufacturers' instructions. 


\subsection{TNF- $\alpha$ and IL-6 ELISA}

To quantify protein expression by ELISA, AC16 cells were seeded at $1 \times 10^{6}$ cells/well in a 6-well plate and preincubated with TAK-242, where indicated, for $1 \mathrm{~h}$ prior to stressEV $(5 \mu \mathrm{g} / \mathrm{mL})$ stimulation for $6 \mathrm{~h}$. Cell culture supernatants were collected and analyzed by Human TNF-alpha DuoSet ELISA and Human IL-6 DuoSet ELISA (R\&D Systems, Minneapolis, MN, USA), according to manufacturers' instructions.

Macrophages were seeded in 96-well plates at $1 \times 10^{5} /$ well. After $24 \mathrm{~h}$, growth media were removed and, where indicated, cells were preincubated with TAK-242 $(2.5 \mu \mathrm{M})$ for $1 \mathrm{~h}$ prior to the addition of stressEVs or LPS. Supernatants were collected after $16 \mathrm{~h}$ and analyzed for IL-6 (Invitrogen).

\subsection{Apoptosis Assay}

For Caspase 3/7 activity measurement, AC16 and H9c2 cells were seeded $1 \times 10^{4}$ cells/well in a white-walled 96-well plate and were stimulated with stressEVs (1, 2, or $5 \mu \mathrm{g} / \mathrm{mL})$ for $4 \mathrm{~h}$. Cells were analyzed for caspase 3/7 activity using the Caspase-Glo 3/7 Assay System (Promega, Madison, WI, USA), according to manufacturers' instructions, on a Varioscan LUX multimode microplate reader (Thermo-Fisher, Waltham, MA, USA).

\subsection{Statistical Analysis}

Values are expressed as means \pm SEM. Statistical analysis was performed between groups by ANOVA with Tukey's post-hoc test or by Kruskal-Wallis One-Way Analysis of Variance on Ranks with Dunn's post-hoc test in the case of datasets with a non-normal distribution (Figure 2B,C,D, Figure 3A,B,E, Figures 5B and 6D) by using GraphPad Prism 8 software. A $p<0.05$ value was considered significant.

Supplementary Materials: The following are available online at http://www.mdpi.com/1422-0067/21/20/7687/s1.

Author Contributions: Conceptualization, supervision, M.M.-K., A.G., P.F., and Z.G.; methodology, data analysis, and visualization, C.T.N., C.P., P.P., B.K., S.H., V.T.H., D.L., G.B.B., and A.K.; writing-original draft preparation, Z.G, S.H., P.F., A.G., P.P., M.B., and M.M.-K.; writing-review and editing, Z.G., M.M.-K., S.H., and P.P. All authors have read and agreed to the published version of the manuscript.

Funding: This research was funded by the National Research, Development and Innovation Office of Hungary (NKFIH; VEKOP-2.3.2-16-2016-00002, TÉT_16-1-2016-0057, National Heart Program NVKP, Grant/Award Number: NVKP_16-1-2016-0017). The research was also financed by the EU COST Action BM1203 EU-ROS, and by the Higher Education Institutional Excellence Programme of the Ministry of Human Capacities in Hungary, within the framework of the Therapeutic development thematic programme of Semmelweis University. This research was funded by grant H2020-SMEInst-2018-2020-1 / SME-1 Project Number: 856235. This research was funded by the Research Excellence Programme of the National Research, Development and InnovationOffice of the Ministry of Innovation and Technology in Hungary (TKP/ITM/NKFIH). M.B. is supported by grants from the Scientific Grant Agency of the Ministry of Education, Science, Research and Sport of the Slovak Republic and the Slovak Academy of Sciences VEGA no. 2/0061/16 and 2/0104/20. Z.G. is supported by a János Bolyai Research Scholarship of the Hungarian Academy of Sciences and by the ÚNKP-19-4 New National Excellence Program of the Ministry of Human Capacities. Slovenian research was funded by the Slovenian Research Agency (research project no. J3-8196 and J3-9257 to M.M.-K.; bilateral project BI-HU/17-18-010 to M.M.-K and Z.G.) and by the H2020-MSC-ETN-642157 project TOLLerant.

Acknowledgments: We are indebted to Tünde Petrovics for her help in conducting the research.

Conflicts of Interest: The authors declare no conflict of interest. 
Abbreviations

\begin{tabular}{|c|c|}
\hline Alix & ALG-2-interacting protein $X$ \\
\hline CD81 & Cluster of differentiation 81 \\
\hline DAMP & Damage-associated molecular pattern \\
\hline DLS & Dynamic light scattering \\
\hline DMEM & Dulbecco's modified Eagle's medium \\
\hline DOAJ & Directory of open access journals \\
\hline DPBS & Dulbecco's phosphate-buffered saline \\
\hline ECACC & The European Collection of Authenticated Cell Cultures \\
\hline ESCRT-III & Endosomal Sorting Complexes Required for Transport-III \\
\hline EV & Extracellular vesicle \\
\hline FBS & Fetal bovine serum \\
\hline HBSS & Hank's Balanced Salt Solution \\
\hline HEK293 & Human embryonal kidney 293 \\
\hline $\mathrm{HO}-1$ & Heme oxygenase 1 \\
\hline HSP & Heat shock protein \\
\hline IL-6 & Interleukin 6 \\
\hline iNOS & Nitric oxide synthase, inducible \\
\hline $\mathrm{I} / \mathrm{R}$ & Ischemia/reperfusion \\
\hline LD & Linear dichroism \\
\hline $\mathrm{LDH}$ & Lactate dehydrogenase \\
\hline LPS & Lipopolysaccharide \\
\hline MD-2 & Lymphocyte antigen 96 \\
\hline MDPI & Multidisciplinary Digital Publishing Institute \\
\hline MLKL & Mixed lineage kinase domain-like protein \\
\hline MyD88 & Myeloid differentiation primary response 88 \\
\hline$N F-k B$ & Nuclear factor kappa-B \\
\hline $\mathrm{NO}$ & Nitric oxide \\
\hline Nrf2/Keap-1 & NF-E2-related factor 2/Kelch-like ECH-associated protein 1 \\
\hline NTA & Nanoparticle tracking analysis \\
\hline oxPL & Oxidized phospholipid \\
\hline PAMP & Pathogen-associated molecular patterns \\
\hline PBS & Phosphate buffered saline \\
\hline PI3K/Akt & Phosphatidylinositol 3-kinase/Akt \\
\hline PKC & Protein kinase $\mathrm{C}$ \\
\hline PRR & Pattern recognition receptor \\
\hline RIC & Remote ischemic conditioning \\
\hline RPMI 1640 & Roswell Park Memorial Institute 1640 Medium \\
\hline TLA & Three letter acronym \\
\hline TLR & Toll-like receptor \\
\hline $\mathrm{TNF} \alpha$ & Tumor necrosis factor alpha \\
\hline $\operatorname{Tr} 1$ & Thioredoxin reductase 1 \\
\hline TSG101 & Tumor susceptibility gene 101 \\
\hline ZnPP IX & Zinc protoporphyrine IX \\
\hline
\end{tabular}

\section{References}

1. Gottlieb, R.A. Cell death pathways in acute ischemia/reperfusion injury. J. Cardiovasc. Pharmacol. Ther. 2011, 16, 233-238. [CrossRef] [PubMed]

2. Heusch, G. Coronary microvascular obstruction: The new frontier in cardioprotection. Basic Res. Cardiol. 2019, 114, 45. [CrossRef] [PubMed]

3. Heusch, G. Critical Issues for the Translation of Cardioprotection. Circ. Res. 2017, 120, 1477-1486. [CrossRef] [PubMed] 
4. Wenzel, R.P.; Streed, S.A. Surveillance and use of computers in hospital infection control. J. Hosp. Infect. 1989, 13, 217-229. [CrossRef]

5. Przyklenk, K.; Whittaker, P. Remote ischemic preconditioning: Current knowledge, unresolved questions, and future priorities. J. Cardiovasc. Pharmacol. Ther. 2011, 16, 255-259. [CrossRef]

6. Davidson, S.M.; Riquelme, J.A.; Takov, K.; Vicencio, J.M.; Boi-Doku, C.; Khoo, V.; Doreth, C.; Radenkovic, D.; Lavandero, S.; Yellon, D.M. Cardioprotection mediated by exosomes is impaired in the setting of type II diabetes but can be rescued by the use of non-diabetic exosomes in vitro. J. Cell Mol. Med. 2018, 22, 141-151. [CrossRef] [PubMed]

7. Schulz, R.; Rose, J.; Post, H.; Heusch, G. Involvement of endogenous adenosine in ischaemic preconditioning in swine. Pflugers Arch. 1995, 430, 273-282. [CrossRef]

8. Lecour, S.; Suleman, N.; Deuchar, G.A.; Somers, S.; Lacerda, L.; Huisamen, B.; Opie, L.H. Pharmacological preconditioning with tumor necrosis factor-alpha activates signal transducer and activator of transcription-3 at reperfusion without involving classic prosurvival kinases (Akt and extracellular signal-regulated kinase). Circulation 2005, 112, 3911-3918. [CrossRef]

9. Caricati-Neto, A.; Errante, P.R.; Menezes-Rodrigues, F.S. Recent Advances in Pharmacological and Non-Pharmacological Strategies of Cardioprotection. Int. J. Mol. Sci. 2019, 20, 4002. [CrossRef]

10. Yanez-Mo, M.; Siljander, P.R.; Andreu, Z.; Zavec, A.B.; Borras, F.E.; Buzas, E.I.; Buzas, K.; Casal, E.; Cappello, F.; Carvalho, J. Biological properties of extracellular vesicles and their physiological functions. J. Extracell Vesicles 2015, 4, 27066. [CrossRef]

11. van Niel, G.; D'Angelo, G.; Raposo, G. Shedding light on the cell biology of extracellular vesicles. Nat. Rev. Mol. Cell Biol. 2018, 19, 213-228. [CrossRef] [PubMed]

12. Hausenloy, D.J.; Garcia-Dorado, D.; Botker, H.E.; Davidson, S.M.; Downey, J.; Engel, F.B.; Jennings, R.; Lecour, S.; Leor, J.; Madonna, R. Novel targets and future strategies for acute cardioprotection: Position Paper of the European Society of Cardiology Working Group on Cellular Biology of the Heart. Cardiovasc. Res. 2017, 113, 564-585. [CrossRef] [PubMed]

13. Davidson, S.M.; Andreadou, I.; Barile, L.; Birnbaum, Y.; Cabrera-Fuentes, H.A.; Cohen, M.V.; Downey, J.M.; Girao, H.; Pagliaro, P.; Penna, C. Circulating blood cells and extracellular vesicles in acute cardioprotection. Cardiovasc. Res. 2019, 115, 1156-1166. [CrossRef] [PubMed]

14. Sluijter, J.P.G.; Davidson, S.M.; Boulanger, C.M.; Buzas, E.I.; de Kleijn, D.P.V.; Engel, F.B.; Giricz, Z.; Hausenloy, D.J.; Kishore, R.; Lecour, S. Extracellular vesicles in diagnostics and therapy of the ischaemic heart: Position Paper from the Working Group on Cellular Biology of the Heart of the European Society of Cardiology. Cardiovasc. Res. 2018, 114, 19-34. [CrossRef] [PubMed]

15. Barile, L.; Moccetti, T.; Marban, E.; Vassalli, G. Roles of exosomes in cardioprotection. Eur. Heart J. 2017, 38, 1372-1379. [CrossRef] [PubMed]

16. Giricz, Z.; Varga, Z.V.; Baranyai, T.; Sipos, P.; Paloczi, K.; Kittel, A.; Buzas, E.I.; Ferdinandy, P. Cardioprotection by remote ischemic preconditioning of the rat heart is mediated by extracellular vesicles. J. Mol. Cell Cardiol. 2014, 68, 75-78. [CrossRef]

17. Bartekova, M.; Jelemensky, M.; Dhalla, N.S. Emerging role of non-coding RNAs and extracellular vesicles in cardioprotection by remote ischemic conditioning of the heart. Rev. Cardiovasc. Med. 2019, 20, 59-71. [CrossRef]

18. Yeang, C.; Hasanally, D.; Que, X.; Hung, M.Y.; Stamenkovic, A.; Chan, D.; Chaudhary, R.; Margulets, V.; Edel, A.L.; Hoshijima, M. Reduction of myocardial ischaemia-reperfusion injury by inactivating oxidized phospholipids. Cardiovasc. Res. 2019, 115, 179-189. [CrossRef]

19. Mancek-Keber, M.; Frank-Bertoncelj, M.; Hafner-Bratkovic, I.; Smole, A.; Zorko, M.; Pirher, N.; Hayer, S.; Kralj-Iglic, V.; Rozman, B.; Ilc, N. Toll-like receptor 4 senses oxidative stress mediated by the oxidation of phospholipids in extracellular vesicles. Sci. Signal 2015, 8, ra60. [CrossRef]

20. Ha, V.T.; Lainscek, D.; Gesslbauer, B.; Jarc-Jovicic, E.; Hyotylainen, T.; Ilc, N.; Lakota, K.; Tomsic, M.; van de Loo, F.A.J.; Bochkov, V. Synergy between 15-lipoxygenase and secreted PLA2 promotes inflammation by formation of TLR4 agonists from extracellular vesicles. Proc. Natl. Acad. Sci. USA 2020, 117, 25679-25689. [CrossRef]

21. Chen, Z.H.; Yoshida, Y.; Saito, Y.; Noguchi, N.; Niki, E. Adaptive response induced by lipid peroxidation products in cell cultures. FEBS Lett. 2006, 580, 479-483. [CrossRef] [PubMed] 
22. Noguchi, N. Role of oxidative stress in adaptive responses in special reference to atherogenesis. J. Clin. Biochem. Nutr. 2008, 43, 131-138. [CrossRef] [PubMed]

23. Kadl, A.; Meher, A.K.; Sharma, P.R.; Lee, M.Y.; Doran, A.C.; Johnstone, S.R.; Elliott, M.R.; Gruber, F.; Han, J.; Chen, W. Identification of a novel macrophage phenotype that develops in response to atherogenic phospholipids via Nrf2. Circ. Res. 2010, 107, 737-746. [CrossRef] [PubMed]

24. Tian, J.; Guo, X.; Liu, X.M.; Liu, L.; Weng, Q.F.; Dong, S.J.; Knowlton, A.A.; Yuan, W.J.; Lin, L. Extracellular HSP60 induces inflammation through activating and up-regulating TLRs in cardiomyocytes. Cardiovasc. Res. 2013, 98, 391-401. [CrossRef] [PubMed]

25. Dolasia, K.; Bisht, M.K.; Pradhan, G.; Udgata, A.; Mukhopadhyay, S. TLRs/NLRs: Shaping the landscape of host immunity. Int. Rev. Immunol. 2018, 37, 3-19. [CrossRef]

26. Lee, S.M.; Hutchinson, M.; Saint, D.A. The role of Toll-like receptor 4 (TLR4) in cardiac ischaemic-reperfusion injury, cardioprotection and preconditioning. Clin. Exp. Pharmacol. Physiol. 2016, 43, 864-871. [CrossRef]

27. Gaspar, R.; Pipicz, M.; Hawchar, F.; Kovacs, D.; Djirackor, L.; Gorbe, A.; Varga, Z.V.; Kiricsi, M.; Petrovski, G.; Gacser, A. The cytoprotective effect of biglycan core protein involves Toll-like receptor 4 signaling in cardiomyocytes. J. Mol. Cell Cardiol. 2016, 99, 138-150. [CrossRef]

28. Ha, T.; Liu, L.; Kelley, J.; Kao, R.; Williams, D.; Li, C. Toll-like receptors: New players in myocardial ischemia/reperfusion injury. Antioxid. Redox Signal 2011, 15, 1875-1893. [CrossRef]

29. Li, C.; Ha, T.; Kelley, J.; Gao, X.; Qiu, Y.; Kao, R.L.; Browder, W.; Williams, D.L. Modulating Toll-like receptor mediated signaling by (1->3)-beta-D-glucan rapidly induces cardioprotection. Cardiovasc. Res. 2004, 61, 538-547. [CrossRef]

30. Gedik, N.; Maciel, L.; Schulte, C.; Skyschally, A.; Heusch, G.; Kleinbongard, P. Cardiomyocyte mitochondria as targets of humoral factors released by remote ischemic preconditioning. Arch. Med. Sci. 2017, 13, 448-458. [CrossRef]

31. Thuy Tran Quang, R.H.; Rousseau, G.; Gosselin, A.A.; Schampaert, E.; Charron, T. Dual effect of pre-ischemic administration of TNF-alpha on myocardial infarct size. World J. Cardiovasc. Dis. 2013, 3, 7. [CrossRef]

32. Vicencio, J.M.; Yellon, D.M.; Sivaraman, V.; Das, D.; Boi-Doku, C.; Arjun, S.; Zheng, Y.; Riquelme, J.A.; Kearney, J.; Sharma, V. Plasma exosomes protect the myocardium from ischemia-reperfusion injury. J. Am. Coll. Cardiol. 2015, 65, 1525-1536. [CrossRef]

33. Pan, J.; Alimujiang, M.; Chen, Q.; Shi, H.; Luo, X. Exosomes derived from miR-146a-modified adipose-derived stem cells attenuate acute myocardial infarction-induced myocardial damage via downregulation of early growth response factor 1. J. Cell Biochem. 2019, 120, 4433-4443. [CrossRef] [PubMed]

34. Onodi, Z.; Pelyhe, C.; Terezia Nagy, C.; Brenner, G.B.; Almasi, L.; Kittel, A.; Mancek-Keber, M.; Ferdinandy, P.; Buzas, E.I.; Giricz, Z. Isolation of High-Purity Extracellular Vesicles by the Combination of Iodixanol Density Gradient Ultracentrifugation and Bind-Elute Chromatography From Blood Plasma. Front Physiol. 2018, 9, 1479. [CrossRef]

35. Sodar, B.W.; Kittel, A.; Paloczi, K.; Vukman, K.V.; Osteikoetxea, X.; Szabo-Taylor, K.; Nemeth, A.; Sperlagh, B.; Baranyai, T.; Giricz, Z. Low-density lipoprotein mimics blood plasma-derived exosomes and microvesicles during isolation and detection. Sci. Rep. 2016, 6, 24316. [CrossRef]

36. Baranyai, T.; Herczeg, K.; Onodi, Z.; Voszka, I.; Modos, K.; Marton, N.; Nagy, G.; Mager, I.; Wood, M.J.; El Andaloussi, S. Isolation of Exosomes from Blood Plasma: Qualitative and Quantitative Comparison of Ultracentrifugation and Size Exclusion Chromatography Methods. PLoS ONE 2015, 10, e0145686. [CrossRef] [PubMed]

37. Li, C.; Wang, J.; Wang, Q.; Zhang, Y.; Zhang, N.; Lu, L.; Wu, Y.; Zhang, Q.; Wang, W.; Wang, Y. Qishen granules inhibit myocardial inflammation injury through regulating arachidonic acid metabolism. Sci. Rep. 2016, 6, 36949. [CrossRef]

38. Pan, L.L.; Liu, X.H.; Gong, Q.H.; Zhu, Y.Z. S-Propargyl-cysteine (SPRC) attenuated lipopolysaccharide-induced inflammatory response in $\mathrm{H} 9 \mathrm{c} 2$ cells involved in a hydrogen sulfide-dependent mechanism. Amino Acids 2011, 41, 205-215. [CrossRef] [PubMed]

39. Collino, M.; Pini, A.; Mugelli, N.; Mastroianni, R.; Bani, D.; Fantozzi, R.; Papucci, L.; Fazi, M.; Masini, E. Beneficial effect of prolonged heme oxygenase 1 activation in a rat model of chronic heart failure. Dis. Model Mech. 2013, 6, 1012-1020. [CrossRef] 
40. Gong, Y.N.; Guy, C.; Olauson, H.; Becker, J.U.; Yang, M.; Fitzgerald, P.; Linkermann, A.; Green, D.R. ESCRT-III Acts Downstream of MLKL to Regulate Necroptotic Cell Death and Its Consequences. Cell 2017, 169, 286-300.e16. [CrossRef]

41. Xie, Q.; Li, X.X.; Zhang, P.; Li, J.C.; Cheng, Y.; Feng, Y.L.; Huang, B.S.; Zhuo, Y.F.; Xu, G.H. Hydrogen gas protects against serum and glucose deprivationinduced myocardial injury in $\mathrm{H} 9 \mathrm{c} 2$ cells through activation of the NFE2related factor 2/heme oxygenase 1 signaling pathway. Mol. Med. Rep. 2014, 10, 1143-1149. [CrossRef] [PubMed]

42. Yang, P.; Zhou, Y.; Xia, Q.; Yao, L.; Chang, X. Astragaloside IV Regulates the PI3K/Akt/HO-1 Signaling Pathway and Inhibits H9c2 Cardiomyocyte Injury Induced by Hypoxia-Reoxygenation. Biol. Pharm. Bull 2019, 42, 721-727. [CrossRef]

43. Yu, H.; Chen, B.; Ren, Q. Baicalin relieves hypoxia-aroused H9c2 cell apoptosis by activating Nrf2/HO-1-mediated HIF1alpha/BNIP3 pathway. Artif. Cells Nanomed. Biotechnol. 2019, 47, 3657-3663. [CrossRef] [PubMed]

44. Issan, Y.; Kornowski, R.; Aravot, D.; Shainberg, A.; Laniado-Schwartzman, M.; Sodhi, K.; Abraham, N.G.; Hochhauser, E. Heme oxygenase-1 induction improves cardiac function following myocardial ischemia by reducing oxidative stress. PLoS ONE 2014, 9, e92246. [CrossRef] [PubMed]

45. Mahmoud, A.M.; Wilkinson, F.L.; McCarthy, E.M.; Moreno-Martinez, D.; Langford-Smith, A.; Romero, M.; Duarte, J.; Alexander, M.Y. Endothelial microparticles prevent lipid-induced endothelial damage via Akt/eNOS signaling and reduced oxidative stress. FASEB J. 2017, 31, 4636-4648. [CrossRef]

46. Subramani, J.; Kundumani-Sridharan, V.; Hilgers, R.H.; Owens, C.; Das, K.C. Thioredoxin Uses a GSH-independent Route to Deglutathionylate Endothelial Nitric-oxide Synthase and Protect against Myocardial Infarction. J. Biol. Chem. 2016, 291, 23374-23389. [CrossRef]

47. Zuurbier, C.J.; Abbate, A.; Cabrera-Fuentes, H.A.; Cohen, M.V.; Collino, M.; de Kleijn, D.P.V.; Downey, J.M.; Pagliaro, P.; Preissner, K.T.; Takahashi, M. Innate immunity as a target for acute cardioprotection. Cardiovasc. Res. 2019, 115, 1131-1142. [CrossRef]

48. Li, X.; Heinzel, F.R.; Boengler, K.; Schulz, R.; Heusch, G. Role of connexin 43 in ischemic preconditioning does not involve intercellular communication through gap junctions. J. Mol. Cell. Cardiol. 2004, 36, 161-163. [CrossRef]

49. Bencsik, P.; Paloczi, J.; Kocsis, G.F.; Pipis, J.; Belecz, I.; Varga, Z.V.; Csonka, C.; Gorbe, A.; Csont, T.; Ferdinandy, P. Moderate inhibition of myocardial matrix metalloproteinase-2 by ilomastat is cardioprotective. Pharmacol. Res. 2014, 80, 36-42. [CrossRef]

Publisher's Note: MDPI stays neutral with regard to jurisdictional claims in published maps and institutional affiliations.

(C) 2020 by the authors. Licensee MDPI, Basel, Switzerland. This article is an open access article distributed under the terms and conditions of the Creative Commons Attribution (CC BY) license (http://creativecommons.org/licenses/by/4.0/). 